\title{
AVALIAÇÃO DE BLOCOS DE CONCRETO PARA ALVENARIA COM ADIÇÃO DE RESÍDUOS DE BORRACHA DE PNEUS
}

\section{EVALUATION OF CONCRETE BLOCKS FOR MASONRY WITH ADDITION OF TIRE RUBBER RESIDUES}

\section{Catiane Sebben Selung'; Mauro Leandro Menegotto²; Andrea Giovana Foltran Menegotto'; Roberto Carlos Pavan²}

\author{
${ }^{1}$ Universidade Comunitária da Região de Chapecó - UNOCHAPECÓ \\ ${ }^{2}$ Universidade Federal da Fronteira Sul - UFFS, Campus Chapecó. E-mail \\ mauromenegotto@gmail.com
}

\begin{abstract}
RESUMO
O constante crescimento do número de veículos de cargas e passageiros em circulação acarreta aumento da quantidade de pneus com necessidade de recapagem ou que se tornam inservíveis. No intuito de contribuir com o melhor aproveitamento dos resíduos de borracha de pneus gerados no processo de recapagem, este estudo foi desenvolvido com o objetivo de avaliar a absorção e resistência à compressão de blocos de concreto para alvenaria, confeccionados com resíduos e agregados encontrados na região oeste do Estado de Santa Catarina. Assim, foram confeccionados blocos de concreto com a substituição parcial de brita por resíduos de borracha nas proporções de $15 \%, 25 \%$ e $35 \%$, em massa, os quais foram comparados com blocos de um traço de referência sem o resíduo. Os resultados dos ensaios confirmaram uma tendência de aumento da absorção e de redução da resistência à compressão dos blocos, com o acréscimo da quantidade de resíduo de borracha de pneus no traço de concreto. A mistura com $15 \%$ de resíduo, no entanto, atendeu o valor mínimo de 3,0 MPa para a resistência característica à compressão de $10 \%$ de absorção máxima, para blocos vazados de concreto simples com função estrutural para alvenaria acima do nível do solo.
\end{abstract}

Palavras-chave: Blocos de Concreto. Resíduos de Borracha de Pneu. Alvenaria Estrutural.

\begin{abstract}
The steady growth in the number of freight and passenger vehicles in circulation causes an increased amount of tires requiring retreading or become useless. In order to contribute to a better utilization of tire rubber residues generated in the retreading process, this paper was conducted with the aim of evaluating the absorption and compressive strength of concrete blocks for masonry, with residues and aggregates found in the western region of Santa Catarina State. Thus, concrete blocks were prepared with partial replacement of coarse aggregate for rubber residues in proportions of $15 \%, 25 \%$ and $35 \%$, in mass, which were compared with blocks of a reference mix without residue. The test results confirmed a tendency to increase the absorption and reduction of the compressive strength of the blocks with the increase of the amount of residues tire rubber in the concrete mix. However, the mixture with $15 \%$ residue satisfies the minimum value of $3.0 \mathrm{MPa}$ for the
\end{abstract}


characteristic compressive strength and a $10 \%$ maximal absorption for hollow concrete blocks with structural function for use in masonry elements above the ground level.

Keywords: Concrete Blocks. Tire Rubber Residues. Structural Masonry.

\section{INTRODUÇÃO}

A utilização de materiais recicláveis na construção civil tem sido uma área em constante desenvolvimento, tanto para destinação ambientalmente correta desses materiais, quanto pela diminuição da necessidade de extração de recursos naturais como matéria-prima. Os produtos resultantes das demolições de edifícios, da fabricação e utilização de plásticos, as cinzas das centrais de alto forno, as escórias e os pneus usados, entre outros, são objetos de estudo e de aplicações em vários países.

Dentre os materiais a reutilizar, os resíduos de pneus têm merecido uma atenção redobrada de modo a propiciar a redução do grave problema ambiental, causado pela sua disposição inadequada. $\mathrm{O}$ constante lançamento de novos modelos de automóveis, as facilidades das formas de pagamento, o incentivo ao consumo, aliados à necessidade de transporte de passageiros e cargas, proporciona um acréscimo do número de veículos em circulação.

Conforme as informações divulgadas pelo Departamento Nacional de Trânsito (BRASIL, 2013), o país possui 76,137 milhões de veículos registrados, o que corresponde a um aumento de $7,93 \%$ nos últimos 12 meses. De acordo com os dados publicados pelo Instituto Brasileiro de Geografia e Estatística, IBGE (2013), a população atual do Brasil é de 198,360 milhões de habitantes. Assim, o país tem em média um veículo para cada 2,61 habitantes. Esse crescimento da frota de veículos, consequentemente, gera aumento da quantidade de pneus com necessidade de recapagem ou que se tornam inservíveis. Mesmo durante o processo de recauchutagem, que prolonga a vida útil do pneu em até 40\% (FIORITI et al., 2010), são gerados resíduos de borracha pela raspagem da banda de rodagem do pneu e que também devem ter uma destinação adequada.

Diversas pesquisas apresentam alternativas para o uso de borracha de pneus em obras de engenharia. Fontes et al. (2010) concluíram que o ligante asfalto-borracha, quando empregado em camadas de revestimento de pavimentos, produz melhorias consideráveis em termos de comportamento elástico e aumento da resistência à fadiga e da resistência à deformação permanente, além da capacidade de retardar a propagação de fendas.

Fioriti e Akasaki (2004) avaliaram a possibilidade do aproveitamento de resíduos de borracha provenientes da recauchutagem de pneus, para a fabricação de blocos de concreto com função estrutural. Observaram a tendência de aumento da absorção e redução da resistência à compressão com o acréscimo do teor de borracha nos blocos ensaiados. Concluíram que a quantidade de resíduos na composição do concreto considerada suficiente, sem que o mesmo venha a diminuir a resistência e ao mesmo tempo apresentar um consumo de cimento de até $300 \mathrm{~kg}$, é de $13 \%$ em volume.

A utilização de resíduos de pneus reciclados em blocos de concreto para alvenaria, também foi avaliada por Santos e Borja (2005). O traço que apresentou maior valor de resistência à compressão foi 1:7,75 (cimento:agregados) com 5\% de resíduo de borracha na sua composição e com fator água/cimento de 0,91, chegando a um valor máximo de 7,09 MPa. Ressaltaram ainda que o resíduo de pneu exerceu uma influência significativa na diminuição da resistência à compressão nos traços com percentuais de $10 \%$ e $15 \%$.

Fioriti et al. (2007) avaliaram o comportamento de blocos de concreto para pavimentação intertravada fabricados com diferentes teores de incorporação de resíduos de borracha, constatando queda da resistência à compressão com o aumento da quantidade de resíduo. Quanto à absorção de água, concluíram que essa propriedade não é afetada de maneira significativa. Nos ensaios de 
resistência ao impacto os blocos apresentaram aumento da capacidade de absorção de energia (tenacidade) com incorporação dos resíduos de borracha.

O reaproveitamento de resíduos de borracha para fabricação de placas pré-moldadas para a construção de unidades habitacionais de custo reduzido foi analisado por Rodriguez et al. (2006). Para avaliar a mobilidade dos compostos químicos inorgânicos a partir das placas produzidas com carga de borracha, foram realizados os testes de lixiviação que demonstraram que o compósito não solubiliza nenhum metal pesado para o meio ambiente.

Pedro et al. (2012) analisaram a influência da incorporação de materiais finos provenientes da trituração de pneus em argamassas para revestimento de paredes. Os resultados mostraram que a incorporação de partículas de borracha é prejudicial à resistência à compressão e à tração na flexão, porém permite às argamassas adquirirem melhor desempenho quanto à deformabilidade e confere maior capacidade de absorverem a energia de impactos.

Mantendo o intuito de contribuir com um melhor aproveitamento dos resíduos de borracha de pneus gerados no processo de recapagem, esta pesquisa foi desenvolvida no sentido de avaliar as propriedades de absorção e resistência à compressão de blocos de concreto para alvenaria, com agregados e resíduos encontrados na região oeste de Santa Catarina.

\section{MATERIAL E MÉTODOS}

Os resíduos de borracha de pneus utilizados nesta pesquisa foram provenientes de uma empresa recuperadora de pneus de médio porte na região de Chapecó, SC. Esses resíduos são gerados por meio de processo mecânico, que utiliza um equipamento composto de cilindros providos de ranhuras, os quais desgastam por raspagem a superfície de rodagem dos pneus usados, para posteriormente ser fixada uma nova banda de rodagem.

Observou-se que este resíduo tem forma variando de arredondada a fibrilar, a qual é influenciada pelo estado da lâmina da raspadeira. No caso de lâmina mais nova extrai lascas maiores e arredondadas e quanto mais desgastadas gera resíduos menores e alongados. A Figura 1 mostra o aspecto do resíduo antes do peneiramento.

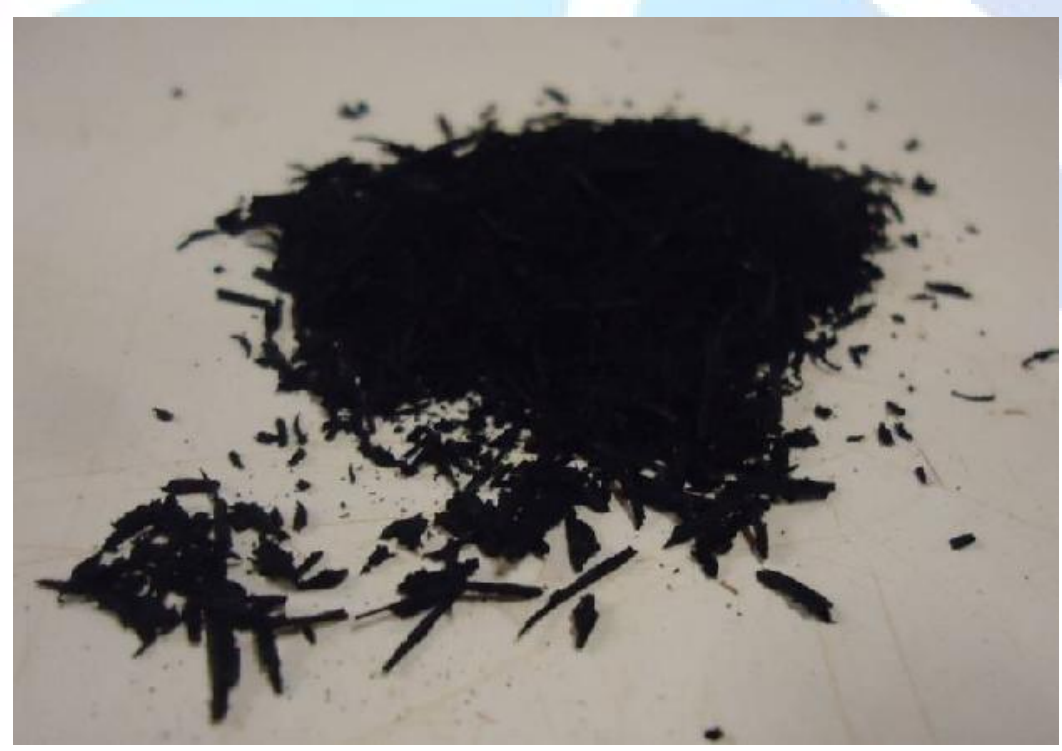

Figura 1. Forma arredondada a fibrilar do resíduo de borracha antes do peneiramento 
Para utilização deste resíduo nos blocos de concreto, o único tratamento realizado foi a retirada por peneiramento das partículas superiores a $4,75 \mathrm{~mm}$. O material passante nesta peneira foi armazenado em tambores de papelão, os quais eram tampados e protegidos das intempéries. Aproximadamente $40 \%$, em massa, do material coletado na empresa ficaram retidos na peneira de 4,75 mm, incluindo impurezas como metais e plásticos que estavam misturados com o resíduo.

Os demais agregados necessários para a confecção dos blocos de concreto, areia natural, areia artificial e a brita 0 foram coletados em uma empresa que confecciona blocos de concreto na região de Chapecó/SC.

O cimento portland utilizado foi o CPII-Z-32, o mesmo utilizado pelas empresas da região para a confecção de blocos de concreto e, também, utilizado por Santos e Borja (2005) em pesquisa semelhante.

Para reduzir a água de amassamento e melhorar o acabamento dos blocos, foi utilizado um aditivo plastificante, recomendado para a confecção de artefatos pré-fabricados com concretos secos. A proporção de aditivo empregado no concreto dos blocos seguiu a especificação do fabricante, sendo utilizados $100 \mathrm{~mL}$ de plastificante para cada $100 \mathrm{~kg}$ de cimento.

Todos os agregados utilizados nesta pesquisa, a areia natural, a areia industrial, a brita e o resíduo de borracha de pneus, foram submetidos aos ensaios de determinação da distribuição granulométrica, massa específica e massa unitária.

A distribuição granulométrica dos agregados e do resíduo foi obtida com base na NBR NM 248 (ABNT, 2003). As massas unitárias dos agregados foram determinadas conforme o método de ensaio da NBR NM 45 (ABNT, 2006) e a determinação das massas específicas dos agregados seguiram as recomendações da NBR NM 52 (ABNT, 2009).

A massa específica da borracha foi determinada utilizando-se um frasco de Chapman e substituindo-se a água por álcool, cuja densidade é de 0,81 , uma vez que com a utilização de água uma parte das partículas de borracha ficou flutuando na superfície, impedindo a leitura correta do volume deslocado. Procedimento semelhante ao adotado por Santos e Borja (2005) que substituíram a água por xilol.

Após a caracterização dos materiais foi realizada a definição do traço de referência para a confecção dos blocos de concreto, sem a adição de resíduos de borracha. A metodologia de dosagem utilizada baseou-se na determinação das porcentagens de cada um dos agregados de tal forma a obter uma mistura com curva granulométrica contínua, ou seja, com os vazios das partículas maiores preenchidos por partículas cada vez menores. Deste modo, na composição granulométrica obteve-se a proporção de $42 \%$ de areia fina, $18 \%$ de areia industrial e $40 \%$ de brita, pela curva granulométrica que melhor se enquadrou nos limites da distribuição granulométrica estabelecidos na NBR 7211 (ABNT, 2009), a qual é uma das referências normativas da NBR 6136 (ABNT, 2007), que dispõe sobre os requisitos de blocos vazados de concreto simples para alvenaria.

A dosagem para os blocos de concreto foi realizada para um traço em massa, adotando-se a proporção de agregado seco de 1:12, conforme traço indicativo recomendado por Medeiros (1993) para uma resistência à compressão média de 4,5 $\mathrm{MPa}$. Assim, o traço de referência considerado na moldagem dos blocos foi 1:5,0: 2,2:4,8 (cimento: areia natural: areia industrial: brita).

Em seguida, foram estabelecidas mais três dosagens com a substituição da brita por resíduo de borracha na proporção de $15 \%, 25 \%$ e $35 \%$, em massa. O traço de referência foi identificado como TR e os demais, conforme sua respectiva porcentagem de resíduo, em T1, T2 e T3.

$\mathrm{Na}$ Tabela 1 encontra-se a composição dos traços em massa correspondentes a materiais secos, utilizados para a confecção dos blocos. No total foram empregados aproximadamente $200 \mathrm{~kg}$ de resíduos de borracha já peneirados. 
Tabela 1 - Traços utilizados nos blocos de concreto com a substituição da brita pelo resíduo.

\begin{tabular}{ccccccc}
\hline & & \multicolumn{5}{c}{ Traço em massa } \\
\cline { 3 - 7 } Identificação & $\begin{array}{c}\text { \% } \\
\text { Resíduo }\end{array}$ & Cimento & $\begin{array}{c}\text { Areia } \\
\text { natural }\end{array}$ & $\begin{array}{c}\text { Areia } \\
\text { industrial }\end{array}$ & Brita & $\begin{array}{c}\text { Resíduo de } \\
\text { borracha }\end{array}$ \\
\hline TR & 0 & 1 & 5,0 & 2,2 & 4,8 & - \\
T1 & 15 & 1 & 5,0 & 2,2 & 4,08 & 0,72 \\
T2 & 25 & 1 & 5,0 & 2,2 & 3,6 & 1,2 \\
T3 & 35 & 1 & 5,0 & 2,2 & 3,12 & 1,68 \\
\hline
\end{tabular}

Com os traços definidos foi iniciada a confecção dos blocos com dimensões correspondentes ao módulo M-15 da NBR 6136 (ABNT, 2007), ou seja, de 140 × 190 × 390 mm. Na fábrica, os agregados foram separados e colocados na esteira que os conduziram até o misturador, onde o maceiro ficava responsável por controlar a quantidade de água colocada na mistura para uma adequada trabalhabilidade do concreto. Ao sair do misturador o material era conduzido até a vibroprensa para a moldagem dos blocos.

Posteriormente, as peças passavam por uma escova giratória para melhorar o seu acabamento superior, em seguida eram empilhadas e conduzidas até o local onde passariam pela cura com o auxílio de uma empilhadeira.

Os blocos empilhados foram logo cobertos por lonas de polietileno de baixa densidade, para se evitar a perda brusca de umidade para o ambiente, permanecendo assim por no mínimo 24 horas. Em seguida foram paletizados, identificados e dispostos no depósito da empresa, onde permaneceram em processo de cura por aspersão de água até o dia antecedente aos ensaios de resistência e absorção.

Durante o preparo do concreto com os diferentes traços com resíduo de borracha, observouse que havia necessidade de colocar mais água nos blocos com maior porcentagem de borracha, para melhor compactação do concreto e garantir o adequado preenchimento das formas e moldagem das peças. Este fato ocorreu devido ao volume de resíduo utilizado ser maior que o volume de brita retirado, necessitando assim mais água para obter-se uma trabalhabilidade adequada.

Assim, para determinação do consumo de água nos blocos, foi coletada uma amostra de cada traço ao final da moldagem. Estas amostras foram acondicionadas em sacos plásticos e conduzidas até o laboratório para a determinação do teor de umidade da massa de concreto e, consequentemente, da relação água/cimento efetiva de cada traço.

De acordo com a NBR 6136 (ABNT, 2007), foram coletadas nove amostras de cada traço, sendo três para realização do ensaio de absorção de água e seis para o ensaio de resistência à compressão, após um período de 28 dias de cura. Para a determinação da absorção, os blocos foram pesados em temperatura ambiente e, em seguida, secados em estufa a uma temperatura de $70{ }^{\circ} \mathrm{C}$ a fim de se evitar a queima da borracha, conforme citado por Borgatto (2010). Os blocos ensaiados para a determinação da resistência à compressão tiveram as faces de trabalho regularizadas por pasta de enxofre no dia antecedente ao rompimento. Os demais procedimentos destes ensaios seguiram as recomendações da NBR 12118 (ABNT, 2011). A Figura 2 mostra um bloco de concreto posicionado na prensa para a execução do ensaio de resistência à compressão. 


\section{RESULTADOS E DISCUSSÃO}

Nos ensaios de granulometria dos materiais empregados na confecção dos blocos de concreto obtiveram-se as curvas granulométricas apresentadas na Figura 3.

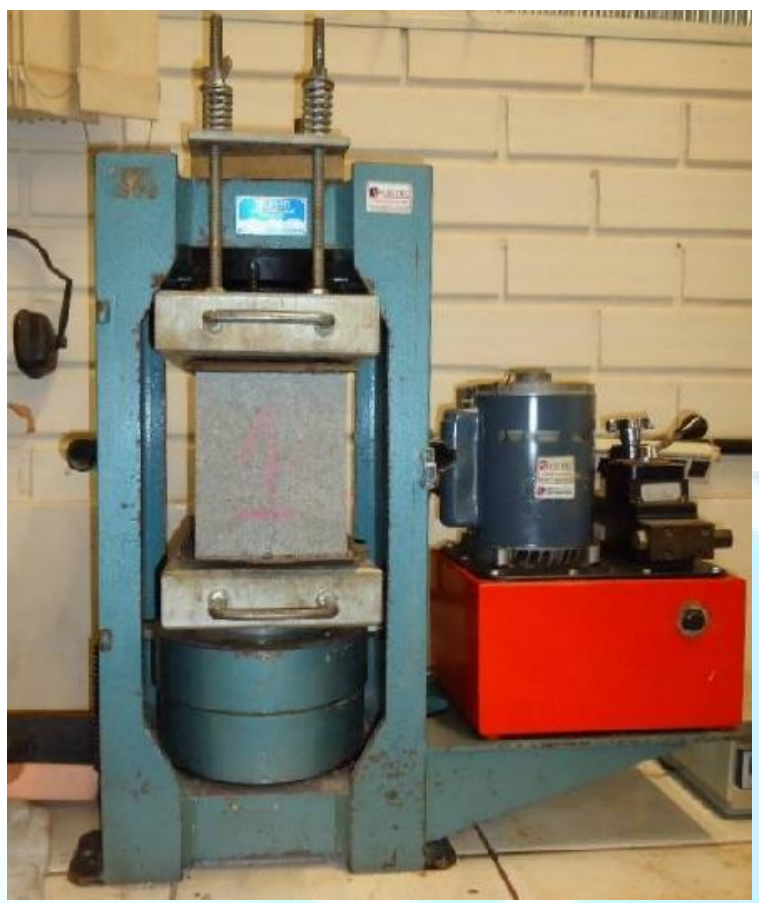

Figura 2. Prensa para o ensaio de resistência à compressão dos blocos de concreto.

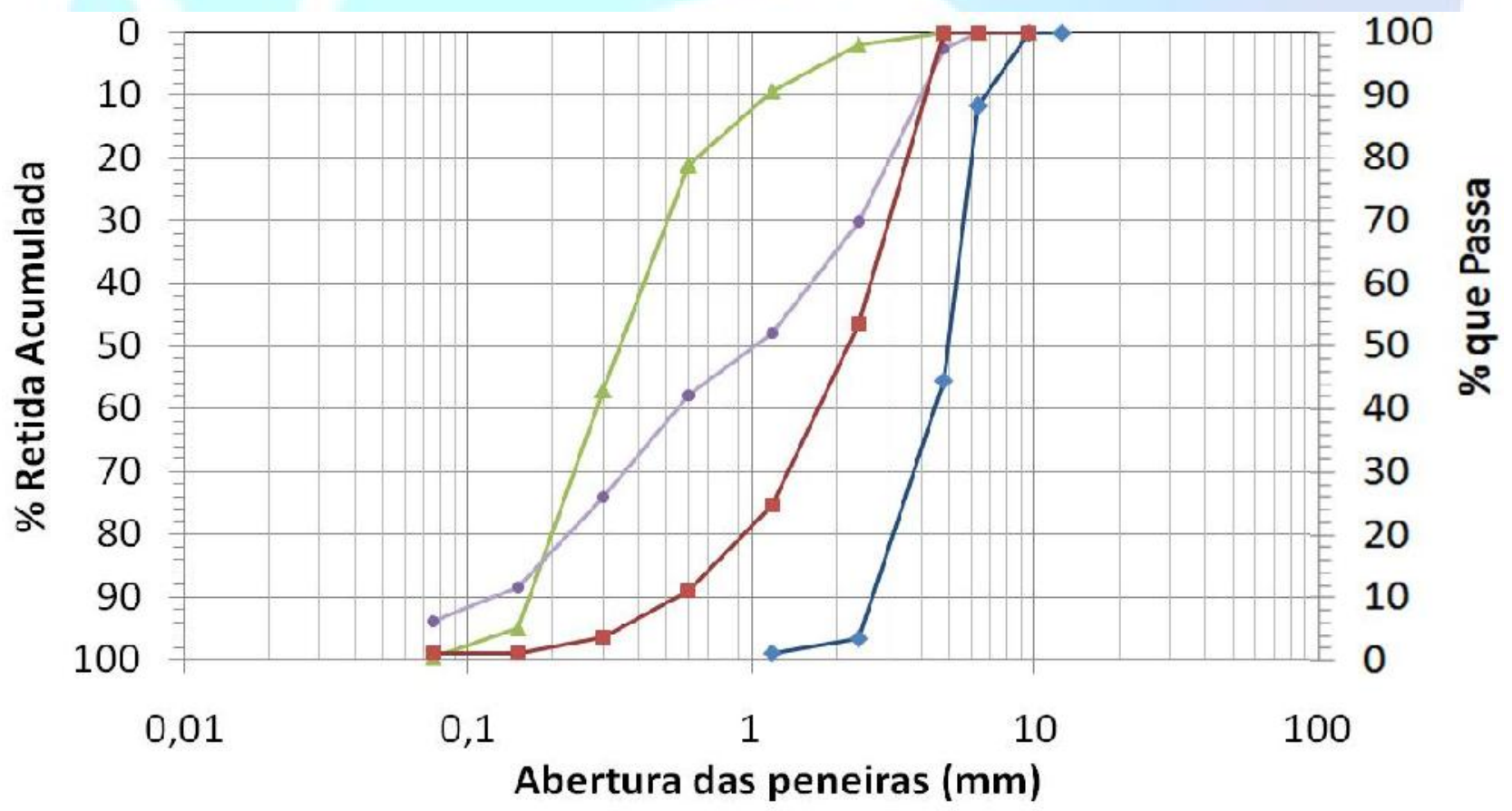

$\rightarrow$ Areia natural $\rightarrow$ Areia industrial $\rightarrow$ Brita $\rightarrow$ Resíduo de borracha

Figura 3. Curvas granulométricas dos materiais utilizados nos blocos. 
Na Tabela 2 encontram-se os resultados do módulo de finura, da dimensão máxima, da massa específica e da massa unitária dos agregados ensaiados.

Tabela 2 - Módulo de finura e dimensões máximas dos agregados.

\begin{tabular}{ccccc}
\hline Agregado & $\begin{array}{c}\text { Módulo de } \\
\text { Finura }\end{array}$ & $\begin{array}{c}\text { Dimensão máxima } \\
(\mathbf{m m})\end{array}$ & $\begin{array}{c}\text { Massa unitária } \\
\left(\mathbf{g} / \mathbf{c m}^{3}\right)\end{array}$ & $\begin{array}{c}\text { Massa específica } \\
\left(\mathbf{g} / \mathbf{c m}^{\mathbf{3}}\right)\end{array}$ \\
\hline Areia natural & 1,85 & 2,36 & 1,518 & 2,648 \\
Areia industrial & 3,01 & 4,75 & 2,200 & 2,778 \\
$\begin{array}{c}\text { Brita } \\
\text { Resíduo de } \\
\text { borracha }\end{array}$ & 2,51 & 9,50 & 1,498 & 2,863 \\
\hline
\end{tabular}

De acordo com a curva granulométrica e com o módulo de finura, a areia natural e a industrial foram classificadas como areia fina e média, respectivamente. A brita, por sua vez, foi classificada como brita $\mathrm{n}^{\mathbf{0}} 0$. Os resíduos de borracha apresentaram uma curva granulométrica intermediária entre areia grossa e brita $\mathrm{n}^{\circ} 0$. O resíduo de borracha apresentou um módulo de finura maior do que os demais agregados, uma vez que a sua curva granulométrica possui uma forma mais contínua, ou seja, com variação maior no tamanho das partículas que o compõem, principalmente nas frações mais finas.

Os resultados obtidos para a massa unitária e massa específica dos resíduos de borracha foram próximos os valores encontrados por Bauer et al. (2001) e Santos (2005), os quais obtiveram massa unitária de 0,50 e $0,30 \mathrm{~g} / \mathrm{cm}^{3}$ e uma massa específica de 1,09 e 1,14 , respectivamente.

$\mathrm{Na}$ Tabela 3 apresentam-se os valores de teor de umidade do concreto e a relação água/cimento efetiva do traço de referência e dos com adição de resíduo. Os resultados mostraram o acréscimo da quantidade de água, e consequentemente da relação água/cimento, com o aumento da quantidade de resíduo no traço, para melhorar o preenchimento das formas e moldagem dos blocos. A substituição da brita por resíduo acarretou aumento da superfície específica devido ao maior volume de partículas de borracha vindo a prejudicar a trabalhabilidade da mistura.

Os valores médios de absorção de água dos blocos, obtidos a partir das três amostras para cada traço analisado, são apresentados na Figura 4. Pode-se observar a tendência de aumento da absorção com o acréscimo da proporção de resíduo de borracha no concreto dos blocos, porém, para todos os traços analisados os resultados ficaram abaixo do limite máximo de absorção de $10 \%$ estabelecido pela NBR 6136 (ABNT, 2007).

Tabela 3 - Relação água/cimento dos traços elaborados

\begin{tabular}{ccc}
\hline Traços & Teor de umidade $(\%)$ & Relação a/c \\
\hline TR & 4,7 & 0,61 \\
T1 & 4,7 & 0,61 \\
T2 & 6,1 & 0,79 \\
T3 & 6,4 & 0,83 \\
\hline
\end{tabular}




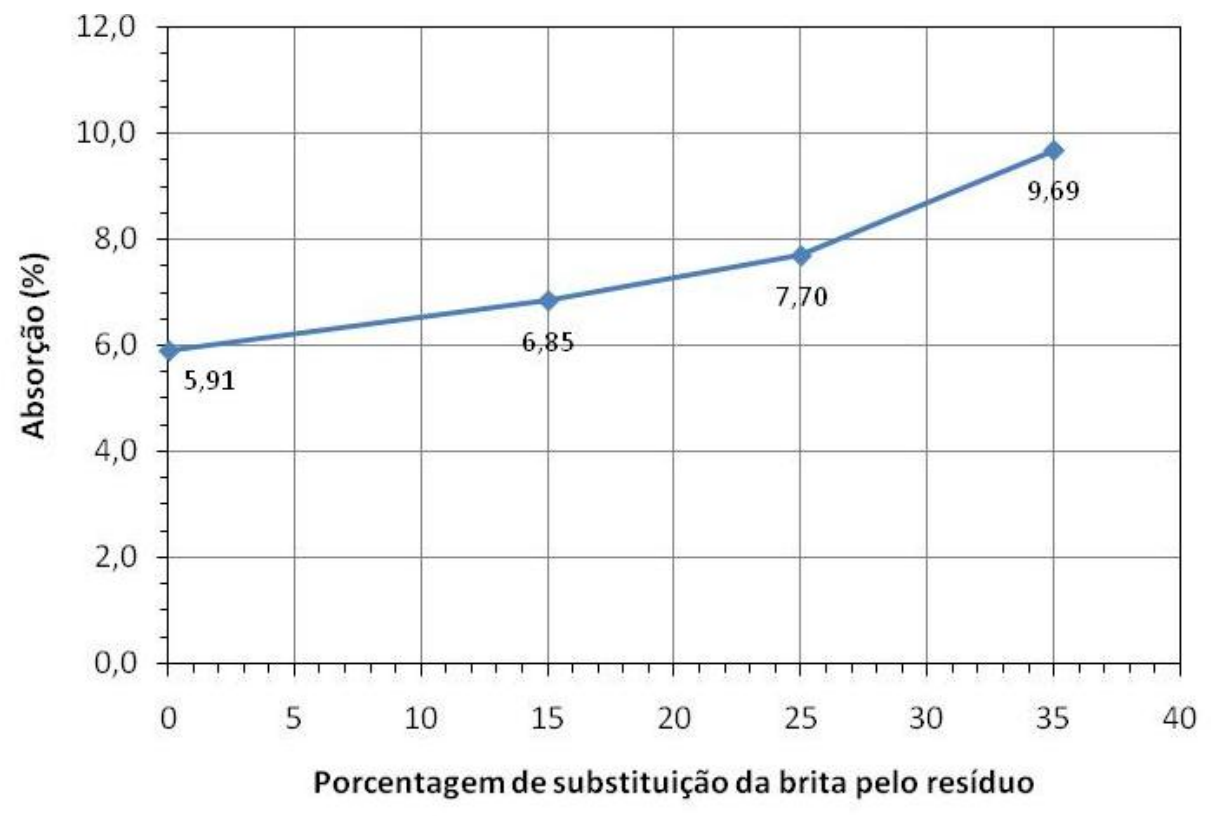

Figura 4. Absorção média dos blocos ensaiados.

Durante o ensaio de absorção determinou-se a massa seca dos blocos analisados. Os valores obtidos são apresentados na Figura 5. Os resultados confirmaram a tendência de diminuição aproximadamente linear da massa do bloco com o aumento da quantidade de resíduo de borracha, uma vez que a esta possui uma massa específica menor do que a da brita e um volume de vazios maior em relação à mesma massa de brita.

Considerando a diferença entre o traço TR e o T1 a redução da massa do bloco foi de 5,2\% em média, cerca de 600 gramas a menos por bloco, que ao se considerar um operário erguendo-o o dia todo pode se tornar bem significativa. Esta redução da massa do bloco também reflete no carregamento total da obra, podendo acarretar também uma economia nas suas fundações.

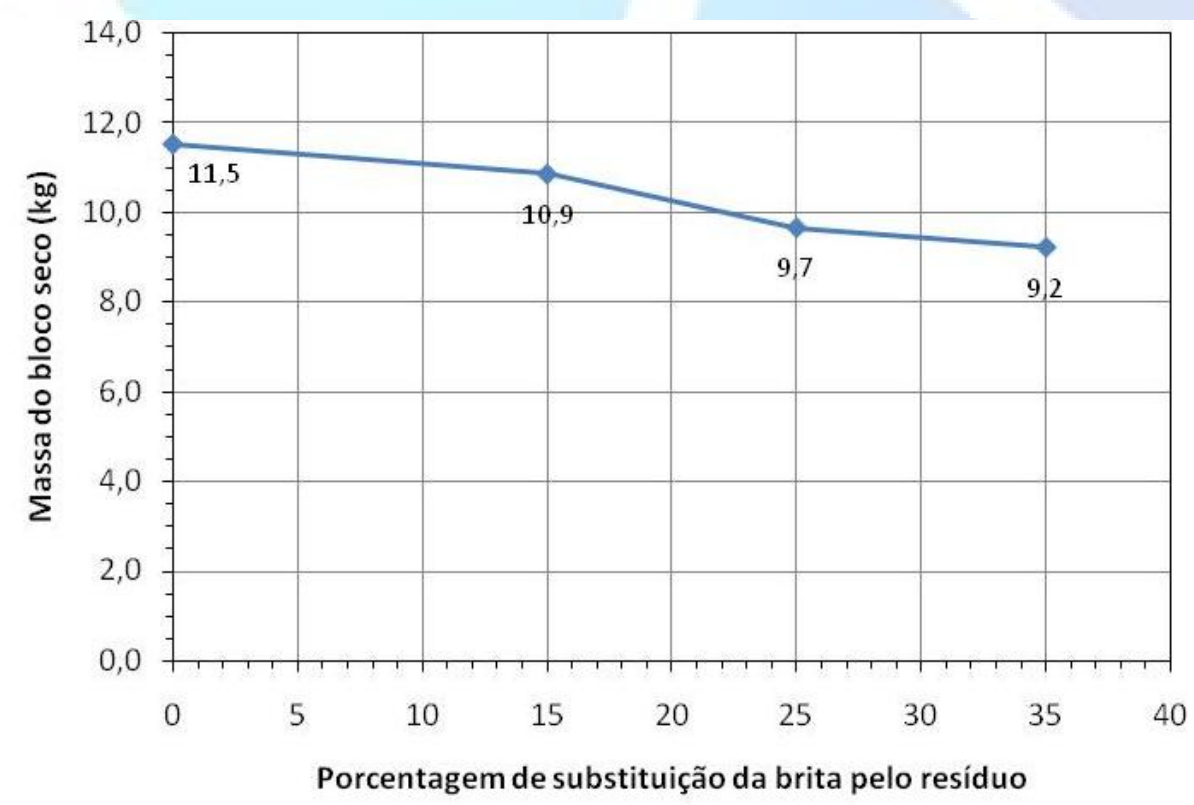

Figura 5. Massa seca média dos três blocos ensaiados em cada traço. 
Os resultados de resistência à compressão média dos seis blocos ensaiados em cada traço, com idade de 28 dias, são apresentados na Figura 6, na qual se observa uma queda brusca na resistência dos traços que possuem borracha moída em relação ao traço referência T1.

Em relação ao traço referência TR, pode-se observar uma tendência de redução significativa da resistência até $25 \%$ de incorporação de resíduo no traço e, posteriormente, mantendo-se praticamente constante até 35\%. A queda de resistência à compressão média do traço T1, T2 e T3, em relação ao TR foi de $51 \%, 88 \%$ e $89 \%$, respectivamente.

Santos e Borja (2005) já haviam constatado que o resíduo de pneu exerce influência significativa na diminuição da resistência à compressão, para um traço com proporção de agregados de 1:11, fator água/cimento de 0,75 e substituição da brita por $10 \%$ de borracha a redução na resistência à compressão média foi de $62 \%$.

Determinou-se também a resistência característica à compressão de cada um dos traços ensaiados, conforme prescrição da NBR 6136 (ABNT, 2007), obtendo-se os valores citados da Tabela 4.

O traço $\mathrm{T} 1$, com $15 \%$ de resíduo, apresentou resistência característica a $47 \%$ inferior a do traço sem resíduo de borracha. Satisfaz, porém, a resistência característica mínima exigida para blocos da classe C, ou seja, 3,0 MPa, para uso com função estrutural em elementos de alvenaria acima do nível do solo. Os blocos confeccionados com os traços T2 e T3 não atendem, no entanto, a especificação da NBR 6136 (ABNT, 2007) para utilização em alvenaria, por apresentarem uma resistência característica inferior a 2,0 MPa, mínimo exigido para a classe D.

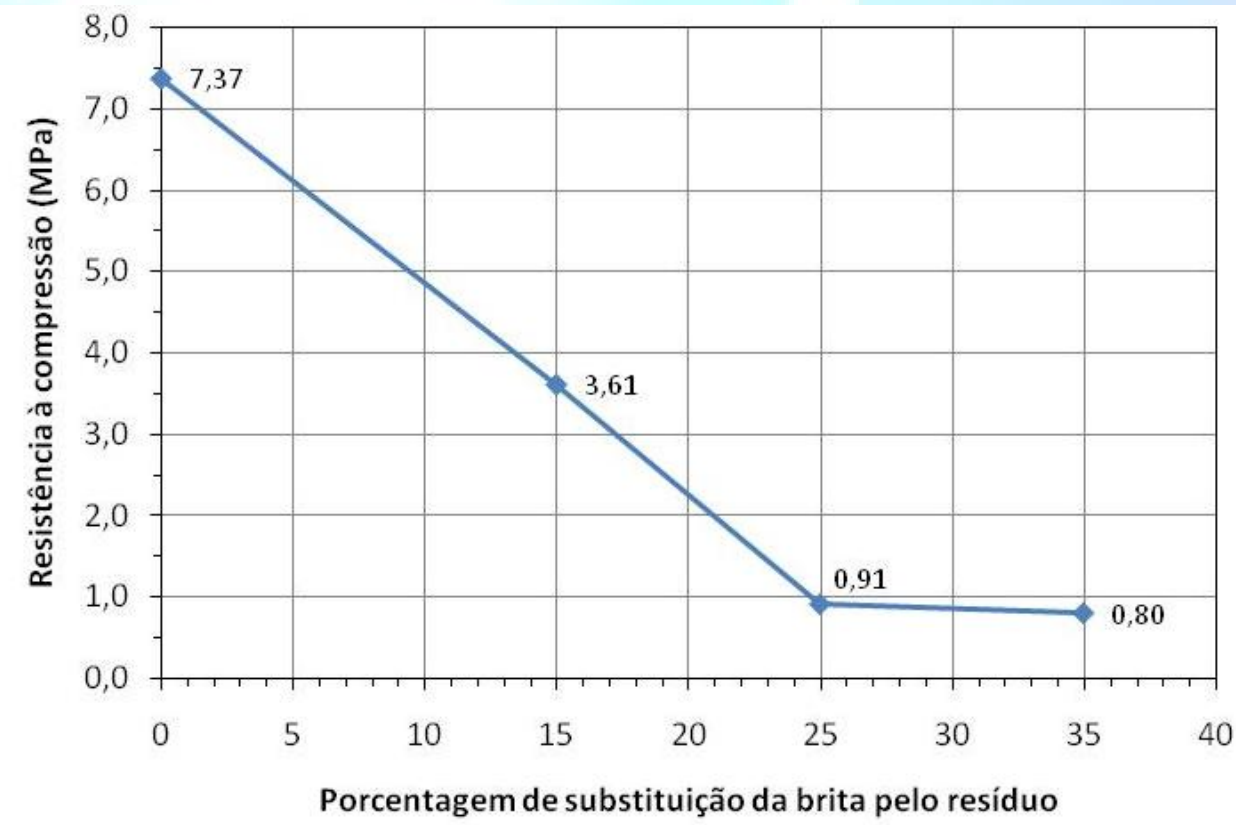

Figura 6. Variação da resistência à compressão média dos blocos com a porcentagem de resíduo.

Tabela 4 - Resistência característica à compressão dos blocos de concreto

\begin{tabular}{cc}
\hline Traços & $\begin{array}{c}\text { Resistência característica } \\
\mathbf{f}_{\text {bk }}(\mathbf{M P a})\end{array}$ \\
\hline $\mathrm{TR}$ & 5,97 \\
$\mathrm{~T} 1$ & 3,14 \\
$\mathrm{~T} 2$ & 0,78 \\
$\mathrm{~T} 3$ & 0,69 \\
\hline
\end{tabular}




\section{CONSIDERAÇÕES FINAIS}

Este estudo analisou a influencia da incorporação de resíduos de borracha, provenientes da recauchutagem de pneus, em blocos de concreto vibro-prensados para utilização em alvenaria. Foram comparados traços de concreto com diferentes taxas de substituição da brita pelo resíduo com um traço de referência sem partículas de borracha.

A redução da massa dos blocos com o acréscimo de resíduo também foi confirmada uma vez que a borracha possui uma massa específica menor em relação à brita, o que favorece o aspecto ergonômico para os trabalhadores e diminui o carregamento total da obra.

Em relação ao ensaio de absorção de água, os resultados mostraram uma tendência de aumento da mesma com o acréscimo da proporção de resíduo de borracha no concreto dos blocos. Todos os traços ensaiados, contudo, encontram-se em conformidade com a absorção máxima o exigida pela NBR 6136 (ABNT, 2007).

A queda dos valores médios e característicos de resistência à compressão dos blocos foi observada em todos os traços com adição de resíduos de borracha, sendo mais pronunciada até $25 \%$ de incorporação de resíduo no traço.

De acordo com a resistência característica dos blocos de concreto, o traço com $15 \%$ de resíduo satisfaz o valor mínimo da NBR 6136 (ABNT, 2007) para blocos com função estrutural para alvenaria acima do nível do solo. Porém, os demais traços analisados não atenderam as especificações de blocos para execução de alvenarias por apresentarem resistência característica inferior ao mínimo exigido pela norma.

\section{AGRADECIMENTOS}

Os autores agradecem ao CNPq, Conselho Nacional de Desenvolvimento Científico e Tecnológico - Brasil, pelo apoio concedido para a realização do presente trabalho.

\section{REFERÊNCIAS}

ABNT - ASSOCIAÇÃO BRASILEIRA DE NORMAS TÉCNICAS. NBR NM 248: Agregados Determinação da composição granulométrica. Rio de Janeiro, 2003.

ABNT - ASSOCIAÇÃO BRASILEIRA DE NORMAS TÉCNICAS. NBR NM 45: Agregados Determinação da massa unitária e do volume de vazios. Rio de Janeiro, 2006.

ABNT - ASSOCIAÇÃO BRASILEIRA DE NORMAS TÉCNICAS. NBR 6136: Blocos vazados de concreto simples para alvenaria - Requisitos. Rio de Janeiro, 2007.

ABNT - ASSOCIAÇÃO BRASILEIRA DE NORMAS TÉCNICAS. NBR 7211: Agregados para concreto - Especificação. Rio de Janeiro, 2009.

ABNT - ASSOCIAÇÃO BRASILEIRA DE NORMAS TÉCNICAS. NBR NM 52: Agregado miúdo - Determinação da massa específica e massa específica aparente. Rio de Janeiro, 2009.

ABNT - ASSOCIAÇÃO BRASILEIRA DE NORMAS TÉCNICAS. NBR 12118: Blocos vazados de concreto simples para alvenaria - Métodos de ensaio. Rio de Janeiro, 2011. 
BAUER, R.J.F.; TOKUDOME, S.; GADRET, A.D. Estudo de concreto com pneu moído. In: CONGRESSO BRASILEIRO DO CONCRETO, 43., Foz do Iguaçu, 2001. Anais... Foz do Iguaçu: IBRACON, 2001. 1 CD-ROM.

BORGATTO, A.V.A. Estudo das propriedades geomecânicas de resíduos sólidos urbanos prétratados. 2010. $271 \mathrm{f}$. Tese (Doutorado) - Universidade Federal do Rio de Janeiro - UFRJ/COPPE, Rio de Janeiro, 2010.

BRASIL. Ministério das Cidades. Departamento Nacional de Trânsito - DENATRAN. Frota 2012. Brasília, 2013. Disponível em: 〈http://www.denatran.gov.br/frota.htm>. Acesso em: 28 jan 2013.

FIORITI, C.F.; AKASAKI, J.L. Fabricação de blocos de concreto com resíduos de borracha de pneus. Holos Environment, Rio Claro, v. 4, n. 2, p. 145-156, 2004. Disponível em:

〈http://www.periodicos.rc.biblioteca.unesp.br/index.php/holos/article/view/349>. Acesso em: 25 ago 2011.

FIORITI, C.F.; INO, A.; AKASAKI, J.L. Avaliação de blocos de concreto para pavimentação intertravada com adição de resíduos de borracha. Ambiente Construído, Porto Alegre, v. 7, n. 4, p. 43-54, out./dez. 2007. Disponível em: 〈http://seer.ufrgs.br/ambienteconstruido/article/view/3753>. Acesso em: 13 mar 2012.

FIORITI, C.F.; INO, A.; AKASAKI, J.L. Análise experimental de blocos intertravados de concreto com adição de resíduos do processo de recauchutagem de pneus. Acta Scientiarum. Technology, Maringá, v. 32, n. 3, p. 237-244, jul./set. 2010. Disponível em:

<http://periodicos.uem.br/ojs/index.php/ActaSciTechnol/article/view/6013 >. Acesso em: 18 jul 2012.

FONTES, L.P.T.L.; TRICHÊS, G.; PAIS, J.C.; PEREIRA, P.A.A. Evaluating permanent deformation in asphalt rubber mixtures. Construction and Building Materials, Publisher Elsevier, v.24(7), p. 1193-1200, 2010.

IBGE - INSTITUTO BRASILEIRO DE GEOGRAFIA E ESTATÍSTICA. Banco de dados. Países@. Brasília, 2013. Disponível em: <http://www.ibge.gov.br/paisesat/main.php>. Acesso em: 28 jan 2013.

MEDEIROS, J.S. Alvenaria estrutural não armada de blocos de concreto: produção de componentes e parâmetros de projeto. 1993. 2v. 20f. Dissertação (Mestrado) - Escola Politécnica, Universidade de São Paulo, São Paulo, 1993.

PEDRO, D.; BRITO, J.; VEIGA, R. Argamassas fabricadas com materiais finos provenientes da trituração de pneus. Teoria e prática na Engenharia Civil, Editora Dunas, n. 19, p.63-76, mai. 2012. Disponível em: 〈http://www.editoradunas.com.br/revistatpec/Art6_N19.pdf>. Acesso em: 05 jul 2012.

RODRIGUEZ, A.L.; LÓPEZ, D.A.R.; VAZ, M.J. Reaproveitamento do resíduo de borracha para fabricação de placas pré-moldadas. In: CONGRESSO BRASILEIRO DE ENGENHARIA E CIÊNCIA DOS MATERIAIS, 17., 2006, Foz do Iguaçu. Anais... Foz do Iguaçu, 2006. p. 1-9. 
SANTOS, A.C. Avaliação do comportamento do concreto com adição de borracha obtida a partir da reciclagem de pneus com a aplicação em placas pré-moldadas. $2005.116 \mathrm{f}$.

Dissertação (Mestrado) - Universidade Federal de Alagoas, Maceió, 2005.

SANTOS, E.A.; BORJA, E.V. Investigação experimental de traços para blocos de concreto para alvenaria de vedação com adição de resíduos de pneus reciclados. Holos Environment, Rio Claro, v.1, p. 54-64, mai. 2005. Disponível em:

<http://www2.ifrn.edu.br/ojs/index.php/HOLOS/article/viewFile/57/63>. Acesso em: 22 ago 2011. 